ORIGINAL ARTICLE

\title{
Are there patterns of bruising in childhood which are diagnostic or suggestive of abuse? A systematic review
}

\author{
S Maguire, M K Mann, J Sibert, A Kemp
}

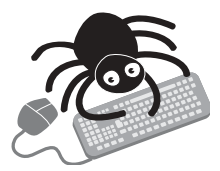

Supplementary material is available on the Archives of Disease in Childhood website (www.archdischild.com/ supplemental)

See end of article for authors' affiliations

.....................

Correspondence to: Dr A Kemp, Department of Child Health, Cardiff University, Wales College of Medicine, Llandough Hospital, Penarth, Wales CF64 2XX, UK; kempam@ cf.ac.uk

Accepted 3 May 2004

\begin{abstract}
Aims: To investigate what patterns of bruising are diagnostic or suggestive of child abuse by means of a systematic review.

Methods: All language literature search 1951-2004. Included: studies that defined patterns of bruising in non-abused or abused children $<18$ years. Excluded: personal practice, review articles, single case reports, inadequate confirmation of abuse. Two independent full text reviews using standardised data extraction and critical appraisal forms. Studies ranked by study design and definition of abuse used.

Results: Twenty three studies included: seven non-abusive bruising, 14 abusive bruising, and two both. Non-abusive: The prevalence, number, and location of bruises is related to increased motor development. Bruising in non-independently mobile babies is very uncommon $(<1 \%)$. Seventeen per cent of infants who are starting to mobilise, $53 \%$ of walkers, and the majority of schoolchildren have bruises. These are small, sustained over bony prominences, and found on the front of the body. Abuse: Bruising is common in children who are abused. Any part of the body is vulnerable. Bruises are away from bony prominences; the commonest site is head and neck (particularly face) followed by the buttocks, trunk, and arms. Bruises are large, commonly multiple, and occur in clusters. They are often associated with other injury types that may be older. Some bruises carry the imprint of the implement used.

Conclusion: When abuse is suspected, bruising must be assessed in the context of medical, social, and developmental history, the explanation given, and the patterns of non-abusive bruising. Bruises in nonmobile infants, over soff tissue areas, that carry the imprint of an implement and multiple bruises of uniform shape are suggestive of abuse. Quality research across the whole spectrum of children is urgently needed.
\end{abstract}

B ruising is the commonest presenting feature of physical abuse in children. ${ }^{12}$ However, it is not easy to distinguish intentional patterns of bruising from the bruises that children sustain from everyday play activities and accidents. Differentiating "normal", non-abusive bruising patterns from abuse is crucial. Most clinicians offer an opinion as to the probability of abuse based on their own clinical experience and textbooks. It is often difficult to give the level of certainty that the child protection agencies or the Court would like. The evidence base to inform this process has not been defined. We have therefore conducted the first systematic review to identify the evidence base and answer the question "What patterns of bruising in childhood are diagnostic or suggestive of abuse?".

\section{METHODS}

\section{Inclusion criteria}

All papers which defined patterns of bruising in non-abused or abused children less than 18 years of age were included. Bites were excluded and will be the subject of a future systematic review. We excluded review articles, expert opinion, single case reports, papers where abuse was not defined, and papers that addressed medical conditions that predispose to bruising. Where appropriate, original data was sought.

\section{Grading the evidence}

Early scanning of studies identified a variety of definitions of abuse and international variation between diagnostic criteria used. The nature of the cases included in abused groups and the level of confidence that abuse was excluded in non-abuse cases has a direct effect on the quality of the study. We have allocated a score to rank the definitions of abuse used ( 1 , abuse confirmed at case conference, civil or criminal court proceedings, or admitted by the perpetrator; 2, abuse confirmed by stated criteria including a multidisciplinary assessment; 3, abuse defined by stated criteria; 4, abuse stated but no supporting detail or evidence given; 5, suspected abuse). In non-abuse papers we have recorded whether factors that influence bruising were excluded, namely abuse, neurodisability, and medical conditions predisposing to bruising.

The diagnostic nature of the question determines that the best possible research studies will be observational and we have ranked papers on study type. We have provided a detailed qualitative summary of the critical appraisal of each paper. The methodological quality of included papers is presented on the $A D C$ website where papers are listed informally according to their importance.

\section{Data sources}

We have conducted an all language literature search of original articles, textbooks, conference abstracts, and references from these and review articles for the period up to October 2004. We used the ASSIA (Applied Social Sciences Index and Abstracts) 1987-2004, Caredata (1980-2004), Medline (1951-2004), Child Data (1958-2004), CINAHL (1982-2004), Embase (1980-2004), ISI Proceedings (19902004), PsycInfo (1987-2004), Science Citation Index (19812004), SIGLE (1980-2004), Social Science Citation Index (1981-2004), and TRIP databases. The search strategy is described on the $A D C$ website. 
Data extraction/validity assessment

A panel of 15 reviewers, all with child protection expertise, conducted two independent full text reviews of each paper. All used standardised criteria for defining the study type and worked to specially devised data extraction, critical appraisal, and evidence forms that were based on criteria defined by the NHS Centre for Reviews and Dissemination. ${ }^{3}$ If there was disagreement between two reviewers the paper was brought to the panel to discuss, and if agreement could not be reached, a third independent review was carried out.

\section{RESULTS}

We sourced 6984 citations; excluding papers for duplicates and irrelevancy there were 1345. Browsing the titles and abstracts we found 161 potentially relevant texts. Six additional papers were identified from references. Twelve papers required translation. After full text review, 23 papers met the inclusion criteria: seven papers addressed patterns of bruising in non-abused children, 14 discussed bruising due to abuse, and two papers compared both. Data from studies was not sufficiently homogeneous to enable a statistical analysis.

\section{Bruising in non-abused children}

Seven of the nine studies ${ }^{4-12}$ addressed the general pattern of bruising in non-abused children, and two ${ }^{12}$ addressed bruises associated with specific injuries, namely fractures and falls from hospital beds. Six of the papers were written primarily about bruises and three contained limited bruising data as part of a wider context. ${ }^{910^{12}}$ There were two case control, four cross sectional, and three case series studies. All had random recruitment, and child abuse; known diseases that predispose to bruising and neurodisability were excluded to a varying degree. Most information applied to children under 10 years of age.

Socioeconomic status was noted in seven papers. There was no difference in bruising in children of different socioeconomic groups. Although ethnicity was recorded in many studies, data were only given in two. Tush ${ }^{6}$ found no significant differences between white and black children, while Sugar and colleagues ${ }^{4}$ found bruising to be significantly more common in white children. However, the ethnic minority population was under-represented in both papers where a mixed ethnic population accounted for under one third of each sample. Tush ${ }^{6}$ found more bruising in boys $(\mathrm{p}<0.05)$. However, combining the data from studies where sex was reported ${ }^{4-6}$ there were no significant differences in gender. Increased accidental bruising was noted in summer ${ }^{10}$ (all ages above 8 months), and with increased family size $(\mathrm{p}>0.05) .^{5}$

Bruises were characteristically small; Carpenter $^{5}$ and Mortimer and Freeman ${ }^{8}$ reported that all bruises were less than 10 and $15 \mathrm{~mm}$ in size respectively. Wedgwood ${ }^{7}$ quotes the mean size of bruises to the head as $12.8 \pm 1 \mathrm{~mm}$, and 5.6$6.8 \mathrm{~mm}$ at other sites. Parents were able to give explanations for 23 of 32 bruises in the Carpenter study, and Mortimer and Freeman ${ }^{8}$ quote explanations in three of six cases that they describe.

The prevalence and mean number of bruising increases with age (table 1). Sugar and colleagues ${ }^{4}$ looked at different developmental stages within 3-month age bands and showed that bruising was directly correlated with motor developmental stage. Carpenter ${ }^{5}$ and Wedgwood ${ }^{7}$ confirm this strong correlation between bruising and mobility in the younger child. Bruising in a baby who has no independent mobility is very uncommon. Wedgwood found no bruising in 11 children whose motor development was no better than crawling, and Sugar and colleagues ${ }^{4}$ identified only two babies (under 6 months old) with scalp bruising. These babies were under 10 days of age and the bruising was almost certainly related to their birth. In contrast bruising is present in the majority of independently mobile preschool and school children.

Studies divided the body into anatomical sites in different ways to report on the distribution of bruising (table 2). As the mobility of the child develops the prevalence of lower leg bruises increases. The commonest sites of bruising in nonabused children who are walking are the knees and shins. ${ }^{467}$ Sugar and colleagues ${ }^{4}$ and Carpenter ${ }^{5}$ noted that bruises were

Table 1 Prevalence of bruising according to age and development when stated

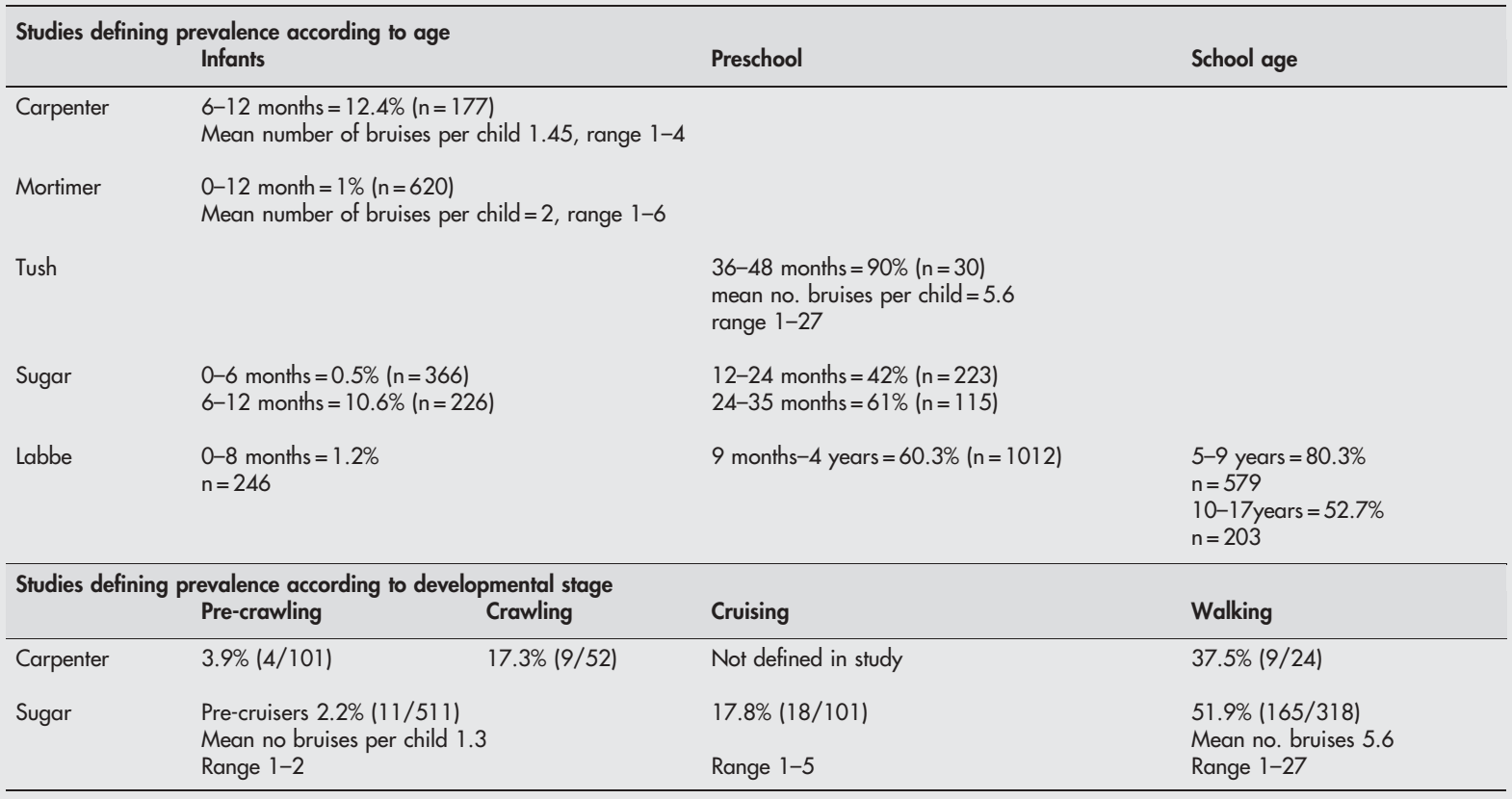




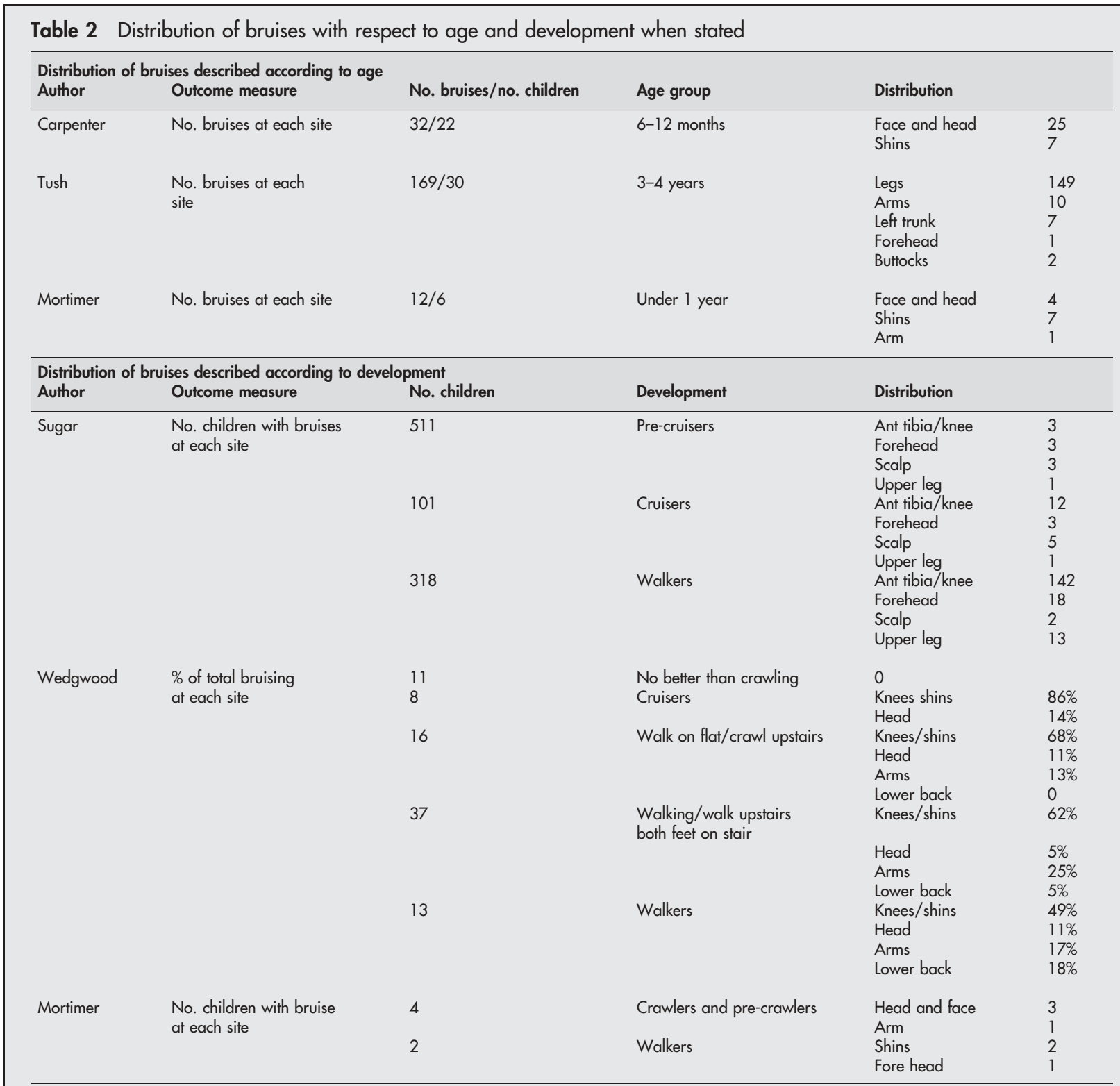

over bony prominences in $93.1-100 \%$ of cases respectively. Bruises were most commonly seen on the front of the body, those to the head usually occurring on the forehead. ${ }^{5}$

There were areas of the body where bruising was uncommon. These sites include the back, buttocks, forearm, face, abdomen or hip, upper arm, posterior leg, or foot where Sugar and colleagues ${ }^{4}$ recorded bruising in less than $2 \%$ of children, at any developmental stage. These uncommon sites for bruising were broadly confirmed in the remaining studies; ${ }^{5-7}$ heterogeneity of anatomical description obviated direct comparisons. Wedgwood ${ }^{7}$ noted bruising to the lower back in the very mobile child, but he saw none in early walkers, cruisers, or pre-cruisers. Forearm bruising was not seen in the cruising and pre-cruising group. ${ }^{457}$ There was no bruising to the hands in children less than 4 years old recorded in any study. Dunstan and colleagues ${ }^{11}$ found no bruising to the ears.

Worlock and colleagues ${ }^{12}$ describe 116 children under 5 years of age with accidental fractures, but only one had significant bruising. Lyons and Oates ${ }^{9}$ studied 207 children under 6 years who fell from hospital beds onto an uncarpeted floor from a height range of 25-54 inches; less than $1 \%$ had contusions.

\section{Bruising in abused children}

Sixteen papers dealt with abused children (see $A D C$ website). Two were case control studies where the definition of abuse ranked highly. Thirteen were case series and one was a cross sectional study. These papers were frequently methodologically weak, either because they were highly selected cases or because the definition of abuse had a low ranking. The age ranges and demography of cases included varied. Only three studies focused primarily on bruising; ${ }^{11}{ }^{13}{ }^{14}$ the majority described soft tissue injuries with some reference to bruising and others looked at injuries to specific parts of the body.

Bruising in child abuse is common; prevalence figures varied widely according to study inclusion criteria ${ }^{1} 212$ 13 $15-17$ (table 3). The mean number of bruises each child sustained varied from 5.7 (controls 1.5$)^{11}$ to 10 (range 0-44) in the populations studied. ${ }^{13}$ Demographic variants noted by 
Johnson and Showers ${ }^{15}$ were that white children are more likely to be bruised than black ( $\mathrm{p}<0.025)$; he found no sex difference. Black children were more likely to be hit by a cord or belt than white children $(p<0.001)$. In contrast white children were more likely to be hit with the open hand or a paddle. Girls were more likely to be struck by the open hand than boys $(\mathrm{p}<0.0001)$.

Bruises can occur among other types of soft tissue injuries. These may be recent or older injuries (for example, scars and healed abrasions). ${ }^{18}{ }^{19}$ The measured lengths of bruises were greater in abused children than controls. ${ }^{11}$

Five studies addressed the distribution of bruises in abuse; all confirmed that the head was the commonest site. ${ }^{111} 121320$ De Silva and Oates ${ }^{20}$ noted multiple bruising to face and head in 53\% (9/17) of fatal child abuse cases and multiple bruising to the trunk and limbs in $41 \%$; only one child had no bruising. Dunstan and colleagues ${ }^{11}$ state that bruising to ear, face, head and neck, trunk and buttocks, and arms is seen significantly more in abuse than controls. Atwal and colleagues ${ }^{13}$ confirmed this distribution of bruises associated with fatal non-accidental head injury (face 19\%, forehead $10.9 \%$, back $8.4 \%$, buttocks $11.7 \%$ ), and Worlock noted that $72 \%$ of bruises in children with non-accidental fractures were on the head and neck. Homicide, ${ }^{12}$ fatal non-accidental head injury, ${ }^{13}$ and non-accidental fractures can occur, however, without external bruising. ${ }^{12}$ In contrast to non-abused children, bruises were seen on soft parts of the body. ${ }^{21}$

A common feature in abused children was clustering of bruises. ${ }^{18}{ }^{19}$ These were often defensive injuries: on the upper arm, outside of the thigh, or bruises on the trunk and adjacent extremity. ${ }^{18}$ Bruises often carry the imprint of the implement used. These include linear or tramline bruising due to being struck with a rod like instrument, ${ }^{15} 181922$ banding where the hand has been tied, ${ }^{22}{ }^{23}$ and an imprint or a negative image of the implement such as an electrical cord or studded belt ${ }^{22}$ or dog collar. ${ }^{18}$ The presence of areas of bruising interspersed with small abrasions was consistent with being hit with a rope. ${ }^{19}$ Vertical gluteal cleft bruising ${ }^{14}$ is described, and bruising to the pinna ${ }^{14} 24$ of the ear, where the profile of the bruise assumes the line of anatomical stress rather than the shape of the injuring object. ${ }^{14}$

\section{DISCUSSION}

We have systematically reviewed the literature and identified the extent of the evidence base that underpins our original question. The nature of the question determines that the studies included were observational in nature. There was only one case control study that compared the general distribution of bruises in abused and non-abused children.

The evidence for bruising patterns in non-abused children primarily addresses children under 10 years of age. The majority of studies were prospective and focused specifically on bruising. The level of published evidence about patterns of bruising in abused children was poorer; the studies that were included dealt with wider issues than bruising. Many papers looked at bruising patterns in specific anatomical areas, in fatal cases, or in narrow age groups of children. Most studies were retrospective and based on the analysis of existing records. The qualitative nature of included studies, variability in study type, methods, and the wide discrepancy in definitions of abuse used prevented us from being able to use a meaningful composite score to directly compare or calculate a hierarchy of studies. The papers that use lower ranking for defining abuse run the risk of reverse causality in defining the abused population.

Studies focused on young able children and predominantly white populations. We included papers with small case series of photographic records. These formed the basis of early influential papers where there were clear descriptions of the abuse that ranked highly and photographs of the injuries that resulted. In this context we felt that their evidential value was still relevant.

Some frequently quoted papers were unsuitable for inclusion. Keen wrote a short letter ${ }^{25}$ detailing bruising patterns in six 3-4 year old children who were repeatedly examined. The study was not methodologically suitable for analysis as there was no detail on ascertainment, exclusion of illness or abuse, methods, or detailed results. Roberton and

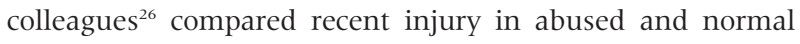
children. They commented that bruising was uncommon in non-abused children 3-9 months of age and increased in prevalence with age. They stated that the hands and lower legs were the most common site of bruising in these children, but no quantitative data were presented. No bruise specific data were given for the abused children. This paper, like many others, described the distribution of soft tissue injury in abused children that was broadly similar to the pattern of bruising. ${ }^{15-18} 27$ Despite the fact that bruising accounted for the majority of these injuries, 56-62\%, ${ }^{17}{ }^{27}$ figures specific to bruising could not be extracted.

From the literature we were able to identify clear differences between bruises sustained after accidents and those that are seen in physical abuse.

Bruising in babies who are not independently mobile is very uncommon $(<1 \%)$. Around $17 \%$ of infants who are crawling or cruising have bruises, whereas the majority of preschool and school children have accidental bruises. These bruises are characteristically small and sustained over bony prominences on the front of the body where they are likely to correspond to falls, the most common cause of childhood injury. ${ }^{27}$ The prevalence, number, and location of bruises are directly linked to motor developmental ability. Children with significant motor development delay would not be expected to have the same bruising pattern as their peer group. This evolving pattern needs to be taken into consideration when assessing bruising in children. Data on explanations for bruises was limited; one paper discussed bruises after falls from hospital beds, and a second, the association of bruises with fractures. Both conclude that even in these specific situations associated bruising is rare.

Table 3 Prevalence figures for bruising in abused children

\begin{tabular}{ll}
\hline Author & Prevalence \\
\hline Lynch & $28 \%$ of school age children with child abuse who have an injury had bruising \\
Galleno & $32 \%$ of children with confirmed physical child abuse have bruises \\
Johnson-Showers & $56 \%$ of children under 17 years with suspected child abuse have bruises \\
Smith-Hanson & $82 \%$ of 134 "battered" children under 5 years old, admitted to hospital had bruises \\
Mcmahon & $92 \%$ of 371 children $(0-18$ years) with suspected child abuse had soft tissue injuries, $62 \%$ of these injuries were bruises \\
& $98 \%$ of 44 infants with suspected child abuse had bruises \\
Worlock & $72 \%$ of children under 5 years with non-accidental fracture had bruising \\
Atwel & $71 \%$ of children with fatal non-accidental head injury have bruises \\
\hline
\end{tabular}




\section{Implications for practice}

A bruise must never be interpreted in isolation and must always be assessed in the context of medical and social history, developmental stage, explanation given, full clinical examination, and relevant investigations.

Patterns of bruising that are suggestive of physical child abuse

- Bruising in children who are not independently mobile

- Bruising in babies

- Bruises that are seen away from bony prominences

- Bruises to the face, back, abdomen, arms, buttocks, ears, and hands

- Multiple bruises in clusters

- Multiple bruises of uniform shape

- Bruises that carry the imprint of implement used or a ligature

In contrast, any part of the body was vulnerable to bruising from abuse. Bruises are located away from bony prominences. They are most commonly seen on the head and neck, particularly the face. The buttocks and back, trunk, and arms are also common sites of injury. Although papers gave relatively little information of mechanism of injury, the histories and photographs of multiple uniform injuries suggested repeated injury to areas of the body that are not commonly bruised accidentally. Abusive bruises are often larger, they are commonly multiple, and occur in clusters. They are often associated with other injury types that may be older. Some bruises carry the imprint of the weapon used.

The one case control study that looked at bruising recognised the significant differences in location and size of bruises between abuse and non-abuse. The authors were able to combine this data mathematically to develop a tool to calculate the probability of abuse. This is a welcome attempt to apply a scientific estimate of probability of abuse, although to apply it in practice would require you to know the prior probability of abuse in your population. Large case control studies encompassing developmental stage in populations representative of ethnic and cultural diversity and children with disability would greatly strengthen the evidence. Further studies exploring the relation of explanations of injury to the pattern of bruising sustained would be valuable.

With the exception of a bruise that carries the clear imprint of the implement used or multiple bruises of uniform shape, there are few bruising patterns that reach diagnostic significance. However, some patterns and locations of bruising are very suggestive of abuse and warrant further exploration. When interpreting the significance of any bruising, it is essential to evaluate the full clinical and social picture and note the developmental level of the child. All bruising must be interpreted in the context of the explanation given. In the court setting, opinion must be solidly based on the evidence available. The expert witness must have an up to date knowledge of the current evidence, its strengths, and limitations.

\section{ACKNOWLEDGEMENTS}

We would like to thank the NSPCC for their support of this systematic review.

\section{Authors' affiliations}

S Maguire, J Sibert, A Kemp, Department of Child Health, Cardiff University, Wales College of Medicine, Llandough Hospital, Penarth, Wales, UK

M K Mann, Support Unit for Research Evidence, Cardiff University, Wales, UK

Competing interests: none declared

Welsh Child Protection Systematic Review Group: M Barber, P Barnes, R Brooks, M James-Ellison, N John, A Maddocks, A Naughton, C Norton, H Payne, L Price, B Ranton, C Woolley

\section{REFERENCES}

1 Smith SM, Hanson R. 134 battered children: a medical and psychological study. BMJ 1974;3:666-70.

2 Lynch A. Child abuse in the school-age population. Journal of School Health 1975:45:141-8.

3 CRD. Undertaking systematic reviews of research on effectiveness. CRD's guidance for those carrying out or commissioning reviews, CRD report number 4, 2nd edn. University of York, 2001.

4 Sugar NF, Taylor JA, Feldman KW. Bruises in infants and toddlers: those who don't cruise rarely bruise. Puget Sound Pediatric Network. Arch Pediatr Adolesc Med 1999;153:399-403.

5 Carpenter RF. The prevalence and distribution of bruising in babies. Arch Dis Child 1999:80:363-6.

6 Tush BAR. Bruising in healthy 3 -year-old children. Matern Child Nurs J 1982;11(23): 165-79.

7 Wedgwood J. Childhood bruises. Practitioner 1990;234:598-601

8 Mortimer PE, Freeman M. Are facial bruises in babies ever accidental? Arch Dis Child 1983;58:75-6.

9 Lyons TJ, Oates K, Falling out of bed: a relatively benign occurrence. Pediatrics 1993;92:125-7.

10 Labbe J, Caouette G. Recent skin injuries in normal children. Pediatrics 2001;108:271-6.

11 Dunstan FD, Guildea ZE, Kontos K, et al. A scoring system for bruise patterns: a tool for identifying abuse. Arch Dis Child 2002;86:330-3.

12 Worlock P, Stower M, Barbor P. Patterns of fractures in accidental and nonaccidental injury in children: a comparative study. BMJ 1986;293:100-2

13 Atwal GS, Rutty GN, Carter N, et al. Bruising in non-accidental head injured children: a retrospective study of the prevalence, distribution and pathological associations in 24 cases. Forensic Sci Int 1998;96:215-30.

14 Feldman KW. Patterned abusive bruises of the buttocks and the pinna. Pediatrics 1992;90:633-6.

15 Johnson CF, Showers J. Injury variables in child abuse. Child Abuse Negl 1985;9:207-15.

16 McMahon P, Grossman W, Gaffney M, et al. Soft tissue injury as an indication of child abuse. J Bone Joint Surg 1995;77A:1179-83.

17 Galleno H, Oppenheim WL. The battered child syndrome revisited. Clin Orthop 1982;162:11-19.

18 Brinkman B, Puschel K, Matzsch T. Forensic dermatological aspects of the battered child syndrome. Akt Dermatolol 1979;5:217-32.

19 Sussman SJ. Skin manifestations in the battered child syndrome. J Pediatr 1968;72:99-100.

20 de Silva S, Oates K. Child homicide-the extreme of child abuse. Med J Aust 1993;158:300-1.

21 Naidoo S. A profile of the oro-facial injuries in child physical abuse at a children's hospital. Child Abuse Negl 2000;24:521-34.

22 Ellerstein NS. The cutaneous manifestations of child abuse. Am J Dis Child 1979;133:906-9.

23 Johnson CF, Kaufman KL, Callendar C. The hand as a target organ in child abuse. Clin Pediatr (Phila) 1990;29(2):66-72.

24 Leavitt EB, Pincus RL, Bukachevsky YR. Otolaryngoloesgic manifestations of child abuse. Arch Otolaryngol Head Neck Surg 1992;1 18:629-31.

25 Keen JH. Normal bruises in pre-school children. Arch Dis Child 1981;56:75.

26 Roberton DM, Barbor P, Hull D. Unusual injury? Recent injury in normal children and children with suspected non accidental injury. BMJ 1982;285:1399-401

27 del Ciampo LA, Ricco RG, De Almeida CA, et al, Incidence of childhood accidents determined in a study based on home surveys. Ann Trop Paediatr $2001 ; 21: 239-43$ 